Quim. Nova, Vol. 34, No. 1, 82-86, 2011

\title{
ESTUDO DA FERMENTAÇÃO DO HIDROLISADO DE BATATA-DOCE UTILIZANDO DIFERENTES LINHAGENS DE Saccharomyces cerevisiae
}

\author{
Marta Cristina de Menezes Pavlak*, Thiago Lucas de Abreu-Lima e Solange Cristina Carreiro \\ Laboratório de Microbiologia e Bioprocessos, Universidade Federal do Tocantins, CP 114, 77001-090 Palmas - TO, Brasil \\ Silene Cristina de Lima Paulillo \\ Fermentec Ltda., Av. Antônia Pizzinato Sturion, 1155, 13420-064 Piracicaba - SP, Brasil
}

Recebido em 23/2/10; aceito em 6/8/10; publicado na web em 16/11/10

\begin{abstract}
STUDY OF FERMENTATION OF THE HYDROLYZATE SWEET POTATO USING DIFFERENT STRAINS OF Saccharomyces cerevisiae. Ethanol is the most suitable substitute for oil-based fuels. The performance of the fermentation is affected by several factors, therefore the aim of this work was to evaluate the efficiency of the fermentation of a hydrolyzed must of sweet potato using three strains of the Saccharomyces cerevisiae. It was also evaluated the effect of three forms of the processes conduction in the fermentation yield, efficiency and viability of yeast at the end process. Among the parameters evaluated, only the cell viability showed significant difference. The strain PE-2 would be the most suitable for the fermentation of the hydrolysed sweet potato.
\end{abstract}

Keywords: ethanol; starch; yield.

\section{INTRODUÇÃO}

Desde a primeira crise do petróleo, em 1970, e com o surgimento do ProÁlcool, a produção de biocombustíveis vem sendo cogitada como parte de uma solução duradoura para o problema energético mundial. ${ }^{1}$

O etanol é produzido principalmente a partir de fontes renováveis, por meio da conversão de açúcares ou de amido. ${ }^{2}$

O Brasil, devido a sua grande variação territorial e diversificação climática, pode usufruir de diversas culturas, muitas delas com características para a produção de etanol. ${ }^{3}$ Entre elas, a batata-doce (Ipomoea batatas L. (Lam.)), que tem se apresentado como uma alternativa viável para a produção de etanol. ${ }^{4}$ Além disso, é mais vantajoso que o etanol da cana-de-açúcar por possuir maior produtividade e por possibilitar a inclusão social do agricultor familiar.

Um aspecto importante durante a fermentação é o modelo de processo fermentativo utilizado. A escolha do processo mais adequado dependerá das propriedades cinéticas dos micro-organismos e tipo de material a ser fermentado, além dos aspectos econômicos. ${ }^{5}$

Nesse sentido, este trabalho teve como objetivos comparar o rendimento e a eficiência do processo fermentativo do mosto hidrolisado de batata-doce, utilizando três linhagens de Saccharomyces cerevisiae, sendo duas linhagens industriais, selecionadas para a fermentação alcoólica, e uma linhagem de panificação e, também, determinar a melhor forma de alimentação das dornas.

\section{PARTE EXPERIMENTAL}

\section{Linhagens de leveduras}

Foram utilizadas três linhagens de Saccharomyces cerevisiae. As linhagens industriais (JP-1 e PE-2) fazem parte da coleção de culturas do Laboratório de Microbiologia e Bioprocessos da Universidade Federal do Tocantins, UFT, e a linhagem de panificação (Fleischmann $^{\circledR}$ ) é a mesma utilizada no procedimento padrão de fermentação de batata-doce da microusina instalada no Laboratório de Sistemas de Produção de Energia a partir de Fontes Renováveis (LASPER).

\footnotetext{
*e-mail: martapavlak@gmail.com
}

A linhagem JP-1 foi isolada em uma destilaria de Japungu - PB. ${ }^{6}$ A linhagem PE-2, nomeada também como S. cerevisiae CCA193, ${ }^{7}$ foi isolada, em 1996 pela Fermentec Ltda, na Usina da Pedra, situada no município de Serrana - SP, ${ }^{8}$ e atualmente é a levedura mais utilizada para produção de etanol no Brasil, segundo Flores (LNF Latino America - responsável pela comercialização desta levedura, comunicação pessoal).

\section{Preparo do inóculo}

As leveduras, mantidas a $-20{ }^{\circ} \mathrm{C}$, foram reativadas em placas com Ágar Sabouraud-glicose (2\% de glicose; $1 \%$ peptona; $0,5 \%$ de extrato de levedura; $1,8 \%$ de ágar), pela técnica de estriamento, e incubadas a $25{ }^{\circ} \mathrm{C}$ por $48 \mathrm{~h}$. Após o desenvolvimento das leveduras, estas foram cultivadas em mosto de caldo-de-cana estéril diluído em água destilada até a concentração de $5^{\circ}$ Brix, enriquecido com $0,5 \%$ de extrato de levedura e mantidos a $30^{\circ} \mathrm{C}$, sob agitação de 150 rpm em shaker (Tecnal, modelo TE-421). Nas primeiras $24 \mathrm{~h}$, foi realizado o crescimento em 4 erlenmeyers de $500 \mathrm{~mL}$, contendo 250 $\mathrm{mL}$ de mosto de caldo-de-cana diluído e estéril. Após o consumo dos açúcares, que foi acompanhado pelo decréscimo do ${ }^{\circ}$ Brix, o conteúdo dos frascos foi transferido para um pré-multiplicador juntamente com $2 \mathrm{~L}$ de mosto de caldo-de-cana a $5^{\circ}$ Brix estéril. Após o consumo dos açúcares, foram acrescentados ao pré-multiplicador $6 \mathrm{~L}$ de mosto de caldo-de-cana estéril, na concentração de $10^{\circ}$ Brix.

Após o consumo do açúcar disponível no meio de crescimento, o inóculo foi decantado e a concentração utilizada para iniciar a fermentação foi padronizada em $10 \mathrm{~g}$ de biomassa (peso úmido) por litro de mosto.

\section{Preparo do mosto de fermentação}

A cultivar de batata-doce escolhida para esse experimento foi a denominada "Duda", que é uma cultivar de película externa roxa e polpa branca, de formato irregular, alongado, redondo e muito desuniforme. A produtividade média obtida, nos últimos 5 anos, foi de $65,5 \mathrm{t} / \mathrm{h}$. O teor de matéria seca é de $40,4 \%$, podendo conferir neste caso rendimentos de $161,04 \mathrm{~L}$ de etanol por tonelada de raiz. ${ }^{4}$ 
O preparo do mosto para fermentação seguiu o protocolo utilizado pelo Laboratório de Sistemas de Produção de Energia a partir de Fontes Renováveis (LASPER).

A Figura 1 mostra o fluxograma para a produção do mosto de batata-doce.

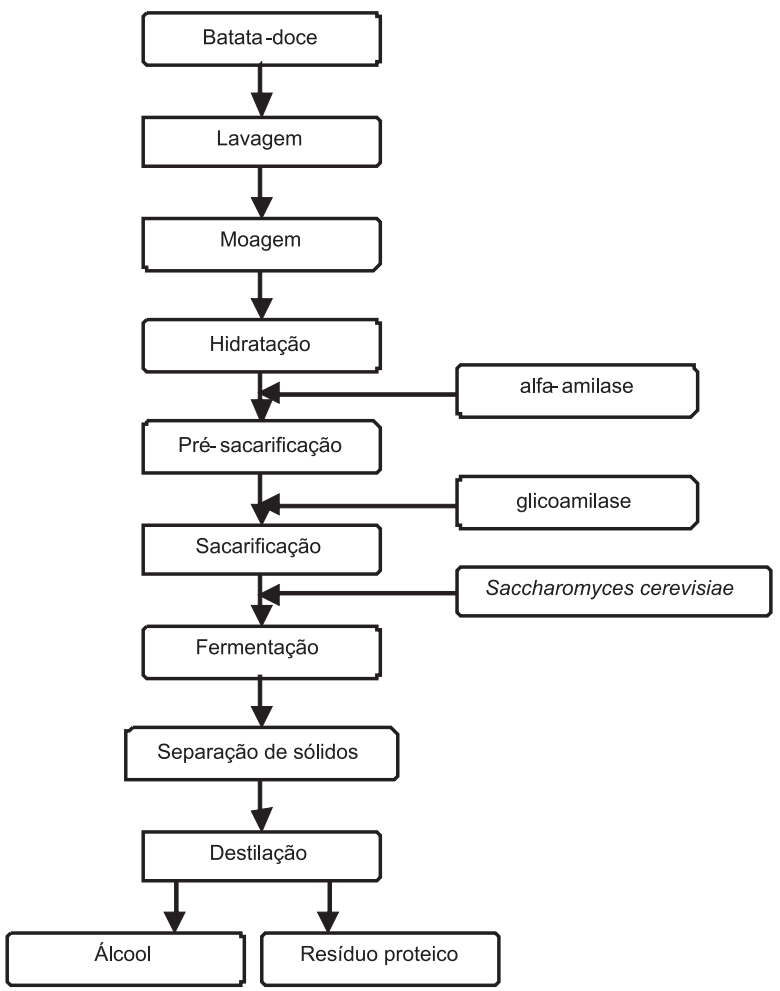

Figura 1. Fluxograma de produção do etanol de batata-doce. Adaptado da ref. 4 e INPI (2009)

Para obtenção do hidrolisado de batata-doce, primeiramente a matéria-prima foi submetida à lavagem e trituração. A batata triturada foi misturada com água na razão 1:1,2.

Logo após, a mistura foi submetida a aquecimento a $90{ }^{\circ} \mathrm{C}$ para geleificação do amido. Quando a temperatura de $90{ }^{\circ} \mathrm{C}$ foi alcançada, adicionou-se a enzima $\alpha$-amilase (Termamyl $120 \mathrm{~L}^{\circledR}$ ), na concentração de $1,5 \mathrm{~mL} / \mathrm{kg}$ de batata, e a mistura foi mantida nessa temperatura por $1 \mathrm{~h}$, para hidrólise da cadeia linear do amido. Em seguida, o pH foi ajustado com ácido clorídrico $1 \mathrm{M}$ para as condições ótimas de atuação da enzima glicoamilase, entre 4,0 e 4,5. A temperatura foi reduzida para $60{ }^{\circ} \mathrm{C}$ e a enzima amiloglucosidase (AMG $300^{\circledR}$ ) foi adicionada, na concentração de $1,5 \mathrm{~mL} /$ $\mathrm{kg}$ de batata. Essa temperatura foi mantida por $1 \mathrm{~h}$, a fim de que as dextrinas produzidas pela primeira enzima pudessem ser hidrolisadas em monômeros de glicose.

Após concluída a etapa de hidrólise, o mosto foi resfriado até aproximadamente $30^{\circ} \mathrm{C}$, a concentração de sólidos solúveis foi ajustada para $12^{\circ}$ Brix com água e o inóculo foi adicionado. $\mathrm{O}$ pH final do mosto ficou entre 4,0 e 5,0, faixa ótima de atuação da levedura.

Todo o processo de produção do mosto foi conduzido na microusina de batata-doce do LASPER. A fermentação foi conduzida em temperatura ambiente por $36 \mathrm{~h}$.

\section{Condução da fermentação}

A fermentação foi conduzida em batelada. Em cada batelada foram utilizados 5,0 L de hidrolisado de batata-doce. A batelada alimentada foi realizada com uma e com duas alimentações.
Na primeira, a fermentação teve início com 2,5 L de hidrolisado, sendo adicionado o restante após $18 \mathrm{~h}$ de fermentação. No processo de batelada alimentada com duas alimentações, a fermentação foi iniciada com 2,0 L de hidrolisado, sendo adicionados a cada intervalo de $12 \mathrm{~h}, 1,5 \mathrm{~L}$ de hidrolisado.

Decorrido o tempo de fermentação, alíquotas foram recolhidas com o objetivo de se analisar os teores de açúcares redutores, a concentração de sólidos solúveis, concentração de etanol e viabilidade celular.

\section{Métodos analíticos}

A concentração de açúcares redutores foi determinada antes e após o processo fermentativo, seguindo a metodologia descrita por Miller, ${ }^{9}$ utilizando-se o método do ácido 3,5-dinitrosalicílico (DNS).

Os sólidos solúveis foram medidos com o uso de um refratômetro ótico portátil marca Tecnal - Atago, modelo Atago N1E.

Para as análises de etanol, $25 \mathrm{~mL}$ do mosto fermentado foram destilados por arraste de vapor, utilizando microdestilador de álcool, Mod. TE-012, marca Tecnal. As amostras foram congeladas e enviadas para a empresa Fermentec, situada em Piracicaba - SP, responsável pela determinação da concentração de etanol, utilizando densímetro digital Anton Paar, modelo DMA4500.

A viabilidade celular foi analisada por contagem direta em câmara de Neubauer, utilizando-se coloração diferencial das células pela solução de azul de metileno, em microscópio binocular (Tecnal - Coleman, modelo N107) em aumento de 100x.

\section{Cálculo dos parâmetros fermentativos}

Fator de conversão de substrato em etanol $\left(Y_{p / s}\right)$

$O$ rendimento da fermentação expressa a quantidade de etanol formada por unidade de açúcar consumido e foi calculado de acordo com a Equação 1:

$$
Y_{p / s}=\frac{P_{F}-P_{O}}{S_{T}-S_{R}}
$$

onde: $\mathrm{P}_{\mathrm{F}(\mathrm{g})}=$ massa de etanol final $(\mathrm{g} / 100 \mathrm{~g}) ; \mathrm{P}_{\mathrm{O}(\mathrm{g})}=$ massa de etanol inicial $(\mathrm{g} / 100 \mathrm{~g}) ; \mathrm{S}_{\mathrm{R}(\mathrm{g})}=$ massa de substrato residual no meio $(\mathrm{g} / 100$ $\mathrm{g}) ; \mathrm{S}_{\mathrm{T}(\mathrm{g})}=$ massa de substrato total no meio $(\mathrm{g} / 100 \mathrm{~g})$.

\section{Eficiência do processo fermentativo}

A eficiência das fermentações foi calculada utilizando-se os valores de etanol produzido (g/100 g) e dos açúcares redutores (AR) presentes no caldo (g/100 g), segundo a Equação 2:

$$
\text { Eficiência }(\%)=\frac{Y_{p / s}}{0,511} \times 100
$$

\section{Delineamento estatístico}

O delineamento experimental utilizado foi o de blocos com repetição, de modo que cada processo fermentativo representou um bloco com duas repetições por tratamento (linhagem de levedura). Os dados experimentais foram analisados estatisticamente pelos procedimentos de análise de variância, por meio do programa ASSISTAT ${ }^{\circledR}$. Para efeito de comparação de médias, foi utilizado o teste Tukey, a $1 \%$ e a $5 \%$ de probabilidade.

\section{RESULTADOS E DISCUSSÃO}

A análise de variância dos parâmetros estudados objetivou verificar a influência tanto das leveduras e da forma de condução do 
processo fermentativo, quanto a interação entre essas duas variáveis, conforme pode ser visualizado na Tabela 1.

Tabela 1. Resumo do quadro das análises de variância para viabilidade (\%), rendimento $(\mathrm{g} / \mathrm{g})$, eficiência $(\%)$ e balanço de massa (L/ha) do processo fermentativo do hidrolisado de batata-doce

\begin{tabular}{lccccc}
\hline FV & GL Rendimento & Eficiência & $\begin{array}{c}\text { Balanço de } \\
\text { Massa }\end{array}$ & Viabilidade \\
& & QM & QM & QM & QM \\
\hline Leveduras & 2 & $0,00154 \mathrm{~ns}$ & $65,5729 \mathrm{~ns}$ & $2687505 \mathrm{~ns}$ & $2,45389 * *$ \\
PF & 2 & $0,00184 \mathrm{~ns}$ & $56,0357 \mathrm{~ns}$ & $2300025 \mathrm{~ns}$ & $0,44056 \mathrm{~ns}$ \\
Levedura x PF & 4 & $0,00100 \mathrm{~ns}$ & $28,5189 \mathrm{~ns}$ & $1170523 \mathrm{~ns}$ & $0,59722 *$ \\
Resíduo & 9 & 0,00466 & 183,629 & 7533010 & 0,10667 \\
Total & 17 & & & & \\
CV $(\%)$ & & 14,23988 & 14,44123 & 14,44172 & 0,33127 \\
\hline
\end{tabular}

**significativo ao nível de $1 \%$ de probabilidade; *significativo ao nível de $5 \%$ de probabilidade; ns - não significativo; Abreviações: FV: Fonte de Variação; GL: Grau de Liberdade; QM: Quadrado Médio; CV - Coeficiente de Variação em \%; PF - Processo Fermentativo.

Os coeficientes de variação oscilaram entre 0,33 e 14,44 , revelando assim boa precisão experimental e permitindo que as inferências sobre os resultados sejam seguras.

De acordo com os resultados da análise de variância (Tabela 1), não houve diferença significativa para os parâmetros rendimento, eficiência e balanço de massa. Da mesma forma, não houve interação significativa entre linhagem de levedura e forma de condução do processo fermentativo em relação aos parâmetros estudados.

A Tabela 2 mostra as médias do fator de conversão do substrato em etanol, para as diferentes linhagens da levedura S. cerevisiae.

Tabela 2. Fator de conversão do substrato em etanol $\left(\mathrm{Y}_{\mathrm{p} / \mathrm{s}}\right)$ utilizando diferentes linhagens de $S$. cerevisiae e diferentes processos fermentativos

\begin{tabular}{lcccc}
\hline Levedura & \multicolumn{4}{c}{ Processo Fermentativo } \\
& Batelada & Bat. Alim. 1 & Bat. Alim 2 & Média \\
\hline Panificação & 0,48 & 0,44 & 0,46 & 0,46 \\
JP-1 & 0,50 & 0,43 & 0,48 & 0,47 \\
PE-2 & 0,49 & 0,50 & 0,49 & 0,49 \\
Média & 0,49 & 0,46 & 0,48 & \\
\hline
\end{tabular}

Os valores de máximo e mínimo foram muito próximos, variando de 0,43 a 0,50 , comprovando baixa variação no rendimento do processo fermentativo com as variáveis estudadas.

Valores inferiores aos encontrados neste trabalho foram discutidos por Ribeiro e Horii, ${ }^{10}$ inclusive no tocante à linhagem de panificação, que apresentou desempenho intermediário $(0,44)$ na produção de etanol.

Conforme mostrado na Tabela 2, não houve variação no rendimento do processo fermentativo, mesmo havendo mudanças na forma de alimentação da fermentação, fato que vem em contrariedade ao estudado por Andrietta e Tosetto, ${ }^{11}$ que avaliaram a influência da velocidade de alimentação de substrato em processos de produção de etanol em batelada alimentada. De acordo com os autores, o rendimento fermentativo diminui com o aumento do tempo de enchimento.

Ampla variação foi observada por Souza, ${ }^{12}$ na análise do processo fermentativo do hidrolisado de batata-doce por meio de células imobilizadas para produção de etanol, com rendimentos oscilando entre 0,073 e 0,834 .

A Tabela 3 apresenta os valores para eficiência do processo fermentativo, considerando as variáveis linhagens de levedura e processo fermentativo.

Tabela 3. Eficiência do processo fermentativo (\%) utilizando diferentes linhagens de $S$. cerevisiae e diferentes processos fermentativos

\begin{tabular}{lcccc}
\hline Levedura & \multicolumn{4}{c}{ Processo Fermentativo } \\
& Batelada & Bat. Alim. 1 & Bat. Alim 2 & Média \\
\hline Panificação & 94,8 & 87,6 & 90,8 & 91,1 \\
JP-1 & 98,2 & 85,7 & 95,0 & 93,0 \\
PE-2 & 97,5 & 98,8 & 96,2 & 97,5 \\
Média & 96,8 & 90,7 & 94,0 & \\
\hline
\end{tabular}

Maior eficiência foi obtida pela linhagem PE-2 (97,5\%), seguida da linhagem JP-1 (93,0\%). A linhagem de panificação apresentou menor eficiência de fermentação.

Quanto ao processo fermentativo, melhor eficiência foi obtida com a fermentação em batelada $(96,8 \%)$, seguida pela fermentação em batelada com duas alimentações $(94,0 \%)$. A fermentação em batelada com uma alimentação apresentou menor eficiência de fermentação $(90,7 \%)$.

A linhagem de $S$. cerevisiae PE-2 apresentou eficiência fermentativa superior em qualquer dos processos fermentativos estudados, enquanto as linhagens de panificação e JP-1 mostraram maior eficiência na fermentação em batelada simples.

A linhagem comercial analisada neste trabalho apresentou eficiência média de $91,1 \%$. Souza et al. ${ }^{12}$ estabeleceram um processo fermentativo utilizando células livres de $S$. cerevisiae comercial, a partir de clones de batata-doce selecionados para as condições de Palmas - TO e obtiveram eficiência de $92 \%$ no processo fermentativo, valor muito próximo ao obtido neste estudo. No processo fermentativo de manipueira utilizando $S$. cerevisiae comercial, Urbano et al. ${ }^{13}$ encontraram eficiência de $96,18 \%$, superior aos demais trabalhos analisados. Valores de eficiência inferiores, variando entre 64,2 e 77,5\%, foram encontrados por Loss et al. ${ }^{14}$ ao estudarem a influência de três linhagens comerciais de $S$. cerevisiae na produção de aguardente de milho maltado.

$\mathrm{Na}$ fermentação submersa de diversos substratos amiláceos, Kiransree et $a l .{ }^{15}$ utilizaram duas linhagens termotolerantes de $S$. cerevisiae para avaliar a capacidade de produção de etanol a 37 e 42 ${ }^{\circ} \mathrm{C}$ e notaram maior quantidade de etanol produzido na fermentação de trigo e batata-doce, nas mesmas condições que amido de arroz, de batata, sorgo doce e amido solúvel. Isto corrobora a informação de que batata-doce é um bom substrato para a produção de etanol, quando comparada a outros substratos amiláceos.

A cultivar de batata-doce denominada "Duda" é considerada a mais produtiva para a indústria, nas condições do Tocantins, em função de sua elevada produtividade, por combinar em um único genótipo elevado teor de matéria seca e produtividade. ${ }^{4}$

Ainda de acordo com Silveira, ${ }^{4}$ a produtividade média dessa cultivar é de 65,5 t/ha e a produtividade em etanol gira em torno de $161 \mathrm{~L} / \mathrm{t}$, o que gera uma produção de $10.467 \mathrm{~L}$ de etanol por hectare.

Partindo desses dados, juntamente com dados de composição da batata-doce no que tange à concentração de amido (24,4\%), e dos rendimentos alcoólicos obtidos neste trabalho para as três linhagens de levedura, estabeleceu-se o balanço de massa da produção de etanol de batata-doce (Tabela 4).

Os valores obtidos neste estudo foram superiores aos registrados por Silveira, ${ }^{4}$ variando de 17.354 a $20.007 \mathrm{~L} / \mathrm{ha}$ e inferiores aos encontrados por Santana, ${ }^{16}$ (1860 e 1769 L/ha), na produção de etanol a partir de mandioca utilizando $S$. cerevisiae e $S$. diastaticus, respectivamente. 
Tabela 4. Balanço de massa da produção de etanol a partir do hidrolisado de batata-doce

\begin{tabular}{lcccc}
\hline \multirow{2}{*}{ Levedura } & \multicolumn{4}{c}{ Balanço de massa (L/ha) } \\
& Batelada & Bat. Alim. 1 & Bat. Alim 2 & Média \\
\hline Panificação & $19.195,5$ & $17.746,5$ & $18.389,5$ & $18.443,8$ \\
JP-1 & $19.882,0$ & $17.354,0$ & $19.239,5$ & $18.825,2$ \\
PE-2 & $19.740,5$ & $20.007,0$ & $19.489,5$ & $19.889,0$ \\
Média & $19.606,0$ & $18.369,2$ & $19.039,5$ & \\
\hline
\end{tabular}

A responsabilidade pelo aumento da produtividade em etanol deve-se aos avanços tecnológicos, pois, conforme Goldemberg, ${ }^{17} \mathrm{a}$ produção brasileira de etanol passou de $2.633 \mathrm{~L} / \mathrm{ha}$, em 1977, para $3.811 \mathrm{~L} / \mathrm{ha}$, em 1985 (uma média de aumento anual de 4,3\%). Em 1989, a média de produtividade no Estado de São Paulo era de 4.700 L/ha, aumentando para 5.100 L/ha em 1996.

A produtividade brasileira atual atinge os $6.800 \mathrm{~L} / \mathrm{ha}$ de etanol de cana-de-açúcar, podendo chegar aos $8.000 \mathrm{~L} / \mathrm{ha}$. Com tal produtividade, o Brasil tem os custos mais baixos do mundo. Só para comparar, os Estados Unidos conseguem entre 3.500 e 4.000 L de álcool por hectare, a partir do milho. ${ }^{18}$

Embora a análise estatística não tenha apontado diferença significativa entre os valores de eficiência do processo fermentativo, bem como do balanço de massa para produção de etanol (Tabela 1), é importante ressaltar que, em caso de aumento de escala, a diferença de $6,4 \%$ existente entre a eficiência das linhagens comercial e PE-2 deve ser considerada, ou seja, a cada hectare processado pode haver um acréscimo de aproximadamente $1.500 \mathrm{~L}$ de etanol apenas se efetuando a troca de micro-organismo fermentador.

Faz-se necessário um estudo de viabilidade econômica com a finalidade de mostrar se o ganho com aumento de rendimento em etanol com a linhagem industrial compensaria os gastos com a pré-multiplicação da linhagem na indústria ou com a linhagem liofilizada fornecida por algumas empresas do ramo, pois a linhagem comercial não demanda tais custos, porém, apresenta rendimento inferior.

Outro fator que deve ser analisado é referente à alteração de escala do experimento. Parâmetros como rendimento e eficiência obtidos em bancada tendem a ser maiores, visto que as condições do processo, são mais facilmente controladas. Siqueira et al. ${ }^{19}$ estudaram a produção de etanol a partir de melaço de soja em laboratório, em escala piloto e industrial. Os autores perceberam que o aumento de escala foi satisfatório, embora tenha havido pequenas diminuições, de 169,8 L em escala de laboratório para 163,6 e 162,7 L de etanol por tonelada de melaço em pó, obtidos em escala piloto e industrial, respectivamente.

Ainda analisando a Tabela 1, verificou-se diferença significativa a $1 \%$ de probabilidade pelo teste $\mathrm{F}$ entre as três linhagens de leveduras avaliadas. Estes resultados evidenciam a existência de superioridade na viabilidade celular entre as linhagens estudadas. Considerando-se as formas de condução do processo fermentativo, não houve diferença significativa na viabilidade celular, porém, a análise de variância permitiu a verificação de diferença significativa na interação entre linhagem de levedura e forma de condução do processo fermentativo a $5 \%$ de probabilidade pelo teste $\mathrm{F}$, de forma que se nota variação nos valores da viabilidade celular dependendo da forma com que foi realizada a fermentação e do tipo de levedura que a executou.

A Tabela 5 mostra as médias de viabilidade celular obtidas após $36 \mathrm{~h}$ de fermentação do mosto hidrolisado de batata-doce, utilizando as diferentes linhagens da levedura $S$. cerevisiae, onde é analisada também a influência da forma de condução do processo fermentativo.
Tabela 5. Viabilidade celular (\%) das linhagens estudadas nos diferentes processos fermentativos

\begin{tabular}{lcccc}
\hline Levedura & \multicolumn{4}{c}{ Processo Fermentativo } \\
& Batelada & Bat. Alim. 1 & Bat. Alim 2 & Média \\
\hline Panificação & $98,3 \mathrm{~b}$ & $98,9 \mathrm{a}$ & $97,1 \mathrm{c}$ & $98,1 \mathrm{~B}$ \\
JP-1 & $98,4 \mathrm{ab}$ & $98,3 \mathrm{a}$ & $98,2 \mathrm{~b}$ & $98,3 \mathrm{~B}$ \\
PE-2 & $99,3 \mathrm{a}$ & $99,2 \mathrm{a}$ & $99,5 \mathrm{a}$ & $99,3 \mathrm{~A}$ \\
Média & $98,7 \mathrm{a}$ & $98,8 \mathrm{a}$ & $98,3 \mathrm{a}$ & \\
\hline
\end{tabular}

Médias seguidas pela mesma letra maiúscula na coluna e minúscula na linha, não diferem estatisticamente entre si a 5\% pelo teste de Tukey.

A viabilidade da levedura é, sem dúvida, um aspecto importante no controle da fermentação alcoólica. Quanto maior esse número, melhor será o desempenho do processo. ${ }^{20}$ Os valores de máximo e mínimo demonstram valores muito próximos, variando de 97,1 a $99,5 \%$, comprovando baixa variação na viabilidade celular.

A linhagem PE-2 apresentou maior viabilidade (99,3\%). Já as linhagens JP-1 e de panificação mostraram menor viabilidade celular, 98,1 e $98,3 \%$, respectivamente, não diferindo entre si estatisticamente.

Cherubin et al. ${ }^{21}$ avaliaram a viabilidade celular de três linhagens na fermentação alcoólica quando em cultura mista com contaminantes bacterianos. Os resultados obtidos mostraram que houve redução de viabilidade nos tratamentos realizados com a linhagem de panificação, porém, os tratamentos com a linhagem PE-2 apresentaram menores reduções de viabilidade, não havendo diferença estatística para este item entre as duas linhagens industriais (PE-2 e M26).

As médias de viabilidade celular, quando analisadas as formas de condução do processo fermentativo, variaram entre 98,3 e 98,7\%. Já na interação entre as linhagens de leveduras e as formas de condução do processo fermentativo, as médias variaram entre 97,1 e $99,5 \%$. Os melhores resultados foram obtidos em batelada descontínua alimentada com uma alimentação para as três linhagens. No processo em batelada simples, as leveduras que apresentaram viabilidade celular mais elevada foram as linhagens industriais JP-1 e PE-2. Para batelada descontínua alimentada com duas alimentações, a linhagem que apresentou melhor resultado foi a PE-2.

Na indústria de etanol a partir de cana-de-açúcar é interessante manter altos níveis de viabilidade celular, devido ao fato de haver reciclo de células, o que significa dizer que após a fermentação, as células da levedura são coletadas por centrifugação e tratadas com ácido sulfúrico em $\mathrm{pH}$ 2,0-2,5 por 1-2 h, a fim de reduzir a contaminação bacteriana, e inoculadas novamente em caldo-de-cana. ${ }^{22}$

No processo de produção de etanol a partir de batata-doce, não há a possibilidade de reciclo de células, devido à dificuldade de separação destas do vinhoto, em função da natureza do substrato, que gera um mosto rico em resíduo fibroso. Assim, a cada nova fermentação são inoculadas novas células da levedura, o que faz com que a viabilidade seja sempre alta, pois, nos casos onde ocorre reciclo de células, a viabilidade tende a diminuir a cada novo ciclo de fermentação.

O conteúdo mineral do mosto é um dos fatores que pode influenciar a viabilidade celular. No estudo conduzido por Aranha, ${ }^{23}$ a presença de alumínio na fermentação alcoólica de cana-de-açúcar afetou minimamente a viabilidade da linhagem PE-2, induzindo maior queda na viabilidade da levedura comercial. Tal fato sugere que a linhagem PE-2 seja mais tolerante que a comercial à ação tóxica do alumínio. Malta et al. ${ }^{24}$ analisaram os parâmetros de propagação de $S$. cerevisiae comercial para produção de cachaça de alambique e perceberam que a viabilidade celular não sofreu interferência da presença de micronutrientes (sais de $\mathrm{Cu}, \mathrm{Zn}, \mathrm{Fe}, \mathrm{Mn}$ ).

É comum no processo de fermentação alcoólica a infecção por bactérias contaminantes, o que causa queda da viabilidade celular das 
leveduras e, consequentemente, menor rendimento devido às toxinas e ácidos excretados no mosto. ${ }^{25}$

Oliveira-Freguglia e Horiii ${ }^{26}$ analisaram a viabilidade celular de Saccharomyces cerevisiae em cultura mista com bactérias do gênero Lactobacillus fermentum. Os resultados comparativos entre cultura bacteriana inativada por esterilização e cultura ativa apresentaram reduções de cerca de 46 e $96 \%$ da viabilidade, respectivamente, nas primeiras $12 \mathrm{~h}$ em relação ao controle, que se manteve constante ao nível de $96 \%$. A viabilidade celular de $S$. cerevisiae foi afetada apenas no cultivo misto com L. fermentum ou B. subtilis ativos, que reduziram em 73,5 e 59,2\%, respectivamente, a viabilidade da levedura $S$. cerevisiae.

Ainda não há estudos sobre contaminação ou proliferação bacteriana na produção de etanol a partir de batata-doce. Como o substrato foi submetido a um processo de hidrólise durante $1 \mathrm{~h}$ a 90 ${ }^{\circ} \mathrm{C}$ antes da fermentação, grande parte da população microbiana foi eliminada. Uma pequena parcela das bactérias presentes pode ter formado esporos. Caso esses esporos tenham germinado, estiveram em desvantagem competitiva, já que ocorreu predominância da levedura fermentadora no meio. Como o processo foi conduzido de forma asséptica, considera-se que não ocorreu contaminação. Isso pode explicar os altos valores obtidos para viabilidade celular para todas as linhagens estudadas.

Portanto, a viabilidade, o rendimento e a eficiência do processo fermentativo do presente estudo são promissores para a produção de etanol utilizando batata-doce como matéria-prima, podendo ainda ser sugerida a utilização da linhagem PE-2 no processo, por ter apresentado maiores valores de viabilidade e rendimento do processo fermentativo.

Há pelo menos mais três leveduras atualmente comercializadas para a produção de etanol a partir de cana-de-açúcar, CAT-1, BG-1, SA-1, que também merecem ser avaliadas, principalmente a CAT-1 (isolada pela Fermentec) que já se mostrou promissora para fermentar mosto de cereais (malte, milho, trigo) em trabalho realizado por Amorin Neto et al., ${ }^{27}$ que testaram as leveduras "brasileiras" produtoras de etanol à base de cana-de-açúcar (CAT-1, PE-2, VR-1, BG-1) em fermentações para a produção de whisky escocês.

\section{CONCLUSÃO}

Os parâmetros avaliados não apresentaram diferença significativa para nenhuma das variáveis estudadas, nem para a interação entre elas. Foi possível computar, na análise do balanço de massa, um volume variando entre 17.354 e $20.007 \mathrm{~L}$ de etanol por hectare de batata-doce.

O processo de fermentação em batelada simples pode ser indicado para quaisquer das linhagens e a linhagem PE-2 seria a mais indicada para a fermentação do hidrolisado de batata-doce, pois apresentou rendimento entre 4,5 e 6,4\%, superior em relação às linhagens JP-1 e de panificação, além de ter mostrado maior viabilidade celular.

\section{REFERÊNCIAS}

1. Souza, V.; Cunha, V. S.; Rodrigues, J. M.; Álcool Combustível, Instituto Euvaldo Lodi - Série Indústria em Perspectiva, IEL: Brasília, 2008, cap. 10.
2. Szwarc, A. Em ref. 1, cap. 7 .

3. Marcoccia, R.; Dissertação, Universidade de São Paulo, Brasil, 2008.

4. Silveira, M. A., coord.; Boletim Técnico - UFT, Palmas, Brasil, 2008.

5. Chandel, A. K.; Es, C.; Rudravaram, R.; Narasu, M. L.; Rao, L. V.; Ravindra, P.; Biotechnology and Molecular Biology, 2007, vol. 2, p. 14.

6. Silva Filho, E. A.; Melo, H. F.; Antunes, D. F.; Santos, S. K. B.; Resende, A. M.; Simões, D. A.; Morais Junior, M. A.; J. Industrial Microbioly and Biotechnology 2005, 32, 481.

7. Brunetto, H. G.; Miranda, V.; Ceccato-Antonini, S. R.; Biológico 2006, $68,25$.

8. Basso, L. C.; Amorim, H. V.; Oliveira, A. J.; Lopes, M. L.; Federation of European Microbiological Societies, V. 8, n. 7, 2008, p. 1155.

9. Miller, G. L.; Anal. Chem. 1959, 31, 426.

10. Ribeiro, C. A. F.; Horii, J.; Sci. agric. 1999, 56, n. 2.

11. Andrietta, S. R.; Tosetto, G. M.; Anais do XI VSinaferm - Simpósio Nacional de Fermentação, Florianópolis, Brasil, 2003.

12. Souza, A. F. B. C.; Souza, F. R.; Silveira, M. A.; $1^{\circ}$ Congresso Científico da Universidade Federal do Tocantins, Palmas, Brasil, 2005.

13. Urbano, L. H.; Suman, P. A.; Leonel, M.; Anais do XII Congresso Brasileiro de Mandioca, Paranavaí, Brasil, 2007.

14. Loss, R. A.; MArgarites, A. C.; Farias, D.; Cazarotto, S.; Colla, L. M.; Bertolin, T. E.; Anais da XVI Mostra de Iniciação Científica da Universidade de Passo Fundo, Passo Fundo, Brasil, 2006.

15. Kiransree, N.; Sridhar, M.; Rao, L. V.; Bioprocess Engineering 2000, 22 , 243.

16. Santana, N. B.; Dissertação de Mestrado, Universidade Federal de Viçosa, Brasil, 2007.

17. Goldemberg, J.; São Paulo em Perspectiva 2000, 14, 91.

18. Collato, V.; http://apache.camara.gov.br/portal/arquivos/Camara/internet/ comissoes/ capadr/subcomissoes/rel2agroenergia130808.pdf, acessada em Janeiro e Novembro 2010.

19. Siqueira, P. F.; Karp, S. G; Carvalho, J. C.; Sturm, W.; Rodriguez-Leon, J. A.; Tholozan, J. L.; Singhania, R. R.; Pandey, A.; Soccol, C. R.; Biores. Technol. 2008, 99, 8156.

20. Steckelberg, C.; Sartorato, A.; Andrietta, S. R.; XIV SINAFERM Simpósio Nacional de Fermentação, Florianópolis, Brasil, 2003, vol. 1.

21. Cherubin, R. A.; Cartes, C. L.; Basso, L. C.; Anais do $13^{\circ}$ Encontro de Biólogos do CRBio-1, São Pedro, Brasil, 2002.

22. Wheals, A. E.; Basso, L. C.; Alves, D. M. G.; Amorim, H. V.; Trends Biotechnol. 1999, 17, 482.

23. Aranha, D. A. D.; Dissertação de Mestrado, Universidade de São Paulo, Brasil, 2002.

24. Malta, H. L.; Abreu-Lima, T. L.; Alvarenga, L. M.; Oliveira, E. S.; Congresso Brasileiro de Tecnologia de Alimentos, XX CBCTA, Curitiba, Brasil, 2006.

25. Malta, H. L.; Dissertação de Mestrado,Universidade Federal de Minas Gerais, Brasil, 2006.

26. Skinner, K. A.; Leathers, T. D.; J. Industrial Microbiology and Biotechnology 2004, 31, 401.

27. Oliveira-Freguglia, R. M.; Horii, J.; Sci. agric. 1998, 55, 520.

28. De Amorim Neto, H. B.; Yohannan, B. K.; Bringhurst, T. A.; Brosnan, J. M.; Pearson, S. Y.; Walker, J. W.; Walker, G. M.; Journal of the Institute of Brewing 2009, 115, 198. 